\title{
An overview of the Landsat Data Continuity Mission
}

\author{
James R. Irons*a and John L. Dwyer \\ NASA Goddard Space Flight Center, Greenbelt, MD, USA 20771; \\ bUSGS Earth Resources Observation \& Science Center, Sioux Falls, SD, USA 57198-9801
}

\begin{abstract}
The Landsat Data Contmuity Mission (LDCM) is the follow-on misston to Landsat 7 and will be the eighth mission an the Landsat series. The mission is in developnent via an interagency parnership between the National Aeronatics and Space Administration (NASA) and the Department of Interior (DOD / United States Geological Survey (USGS). The LDCM satellite will carry two earthobserving sensors, the Operational Land lmager (OLD) to collect image data for nine spectral bands in the refiective portion of the spectnum and the Thermal hnfraref Sensor (TIRS) to collect concident image data for two themal spectral bands. The LDCM ground segment will control the satellite and will reecive, process, archive, and distribute the seience data collected by the OLI and TIRS instruments. The USGS Earth Resources Observation \& Science Center (EROS) will distribute LDCM data products at no cost to requestors. The mission objective is to continues the Landsat program's collection, archive, and distribution of multispectral imagery affording global, synoptic, and repetitive coverage of the Earth's land surfaces at a scale where natural and human-induced changes can be detected, differentated, characterized, and monitored over tine. The LDCM launch readiness date is curreltly December, 2012.
\end{abstract}

Keywords: Landsat, data archive, continuity, NASA, USGS

\section{INTRODUCTION}

The Landsat progran has collected and archived multispectral digital images of the global land surface since the launch of Landsat 1 in 1972. Two Landsat satellites remain it1 operation. Landsat 5 remarkably continues to colleet and transmit data from one of its sensors, the Thematic Mapper (TM), 26 years after its 1984 launch with a three year design life. The most recently launched Landsat satelite, Landsat 7 launched in 1999, contintes to collect and transmit data fron its sole instrment, the Enhanced Thematic Mapper-Plus (ETM+), although the data is now compromised by a 2003 failure of a component of the ETM+ optical system, the scan line corrector. The ages and problems with these two satellites create urgency with respect to the development and launch of the next Landsat mission, the landsat Data Continuity Mission (LDCM).

The development of the LDCM has been delayed by a couple altemative implementation strategies that were explored and ultimately abandoned by the U.S. government. The current strategy is to develop and launef a dedicated LDCM satelite as a "free-flyer." In late 2005 the Executive Office of the President directed the Nationa Aeronautics and Space Administration (NASA) and the Department of Interior (DOI) / United States Geological Survey (USGS) to inplement this strategy through an interagency parthership. The two organizations subsequently agreed on roles and responstibilites with the agreement modeled on the partnetship leading to the stecessful development and operation of Landsat 7. NASA is responsible for the development, launch, and initial check-out of the LDCM space segment and oversees the integration of the entire nission architecure. DOUUSGS is responsible for development of the ground system and will assume responsibilty for satellite and ground system operations following the check-out period. Together, the partnership is striving for a December, 2012 launch date with opetational data collection begining it early 2013 in advance of the Northem Hemisphere growing season,

The goal of the LDCM, consistent with U.S. law and govenment poltcy, is to continte the collection, archive, and distribution of multispectral inagery affording global, symoptic, and repetive coverage of the Earth's land surfaces at a scale where natural and humartinduced changes can be detected, differentiated, characterized, and monitored over time. As the successor to Landsat 7 and the earlier Landsat satelltes, the intent is to provide data into the futtre that is sufficienty consisten with previous Landsat data to allow the detection and quantiative characterization of changes in or on the land surface of the globe. Specific mission objectives include: collect and archive moderate resolution (circa $30 \mathrm{~m}$ ground sample distance) multispectral image data affording seasonal eoverage of the global landmass for a 
contintous period of not less than 5 years; ensure that LDCM data are sufficiently consistent with data from the earlyer Landsat missions in tems of acquisition geometry, calibration, coverage characteristics, spectral characteristics, output product quality, and data availability to permit studjes of land cover and land use change over multi-decadal periods; and distribute LDCM data products to the general public on a nondiscriminatory basis and at no cost to the users. The mission will provide Landsat data to the USGS National Satelite Land Remote Sensing Data Archive (NSLRSDA) at USGS Earth Resources Observation \& Scienee Conter (EROS) for at least 5 years. This archive constitutes the longest continuous record of the Earth's surface as seet fron space and is an irreplaceable resource for understanding the changing land surface and ts impact on climate change, the econorny, society, and national security.

\section{MISSION ARCHITECTURE}

The LDCM architecture consists of two major segments: the Space Segment and the Ground System. NASA is responsible for implementing the Space Segment and its major component is the satellite observatory. USGS is responsible for integrating the elements of the ground system including the Ground Network Element (GNE), the Mission Operations Element (MOE), and the Data Processing and Archive System (DPAS).

\subsection{The Satellite Observatory}

The LDCM observatory will consist of the spacecraft bus and its payload of wo Earth observing sensors, the Operational Land Imager (OLI) and the Thenmal Infrared Senser (TIRS). The spacecraft bus and the OLl are being procured through private vendors selected via conpetitive processes. NASA GSFC is building TRS. Both sensors will be delivered to the spacecraft bus vendor for integration as the observatory. OLI and TIRS whll collect he LDCM Soience Data. The two sensors will coincidently collect multispectral digital images of the global land surface including coastal regions, polar ice, islands, and the continental areas. The spacectaft bus wilt store the OLI and TIRS data on an onboard recorter and will transm it data to ground receiving stations.

\subsubsection{The Spacecraft Bus}

NASA awarded a contract for the LDCM spaccraft to General Dynamics Advanced Information Systens (GDAIS) in Apri 2008. Orbital Science Corporation subsequently acquired the spacecraft division of GDALS in April 2010. Orbital Sctences Corporation has thus assumed responsibility for the design and fabrication of the LDCM spaceraft bus, integration of the government furnished instruments, satellite-level testing, on-orbit satellte check-out, and continuing on-orbit enginecring support. They also will provide a spacectaftobservatory simulatot. The contract includes fabrication and testing of the spacecraft with mission specifie design modifications; generation of interface control documents, instrument and full spacecraft integration; testing, sinipment to the latnch site, launch vehicle integration support and on-orbit checkout.

A successful spacecraft critical design review was held in October 2009 . The design notably includes a 3,14 Terra-bit solid-state data recorder and an earth-coverage X-band antenna. The X-band antenna will transmit OLI and TIRS data ether in real tme or played back from the data recorder. Assembly of the spacecraft bus has begun following the design review. 


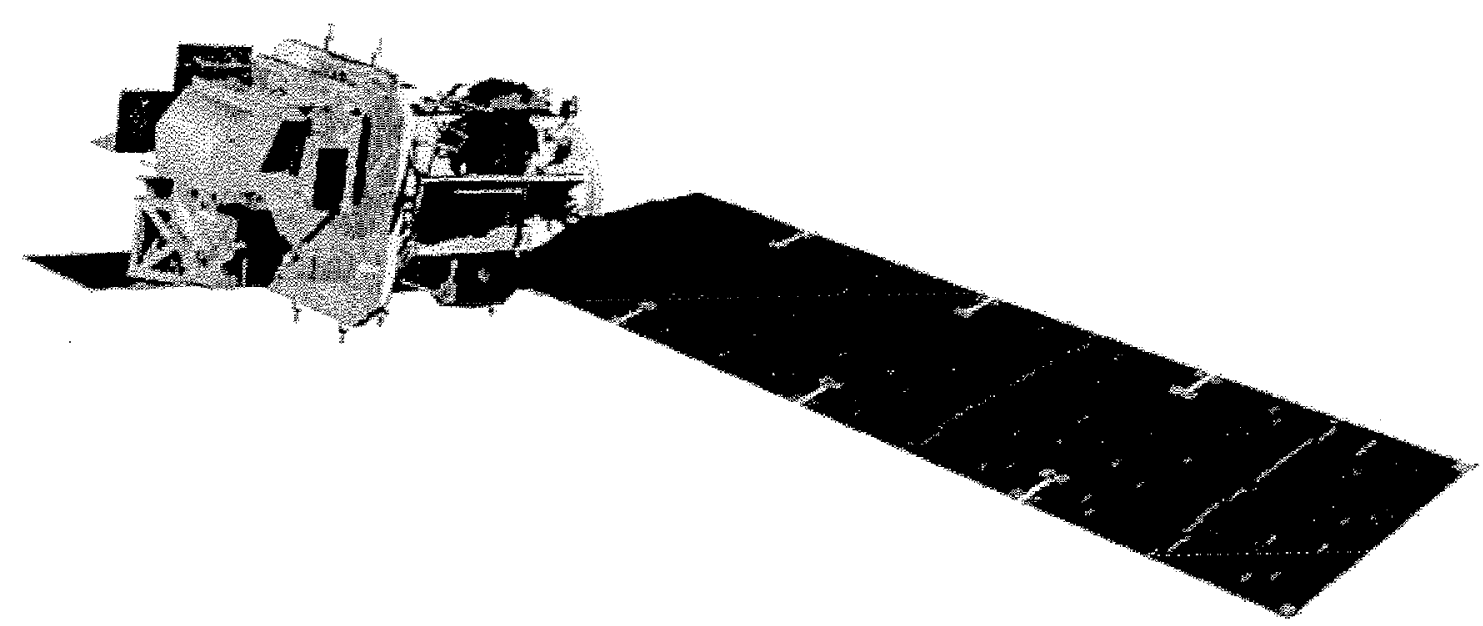

Figure 1. Drawing of the LDCM Satellife Observatory (courtesy of Orbital Sciences Corporation)

\subsubsection{The Operational Land Imager (OLI)}

NASA awarded Ball Aerospace and Technology Corporation a contract for the Operational Land lmage (OLI) in July 2007. The OLI will collee digital image data fot nine shortwave spectral bands (Table 1) across a 185 kn swath from the LDCM observatory. The OLI will provide a $30 \mathrm{~m}$ spatial resolution for eight of the spectral bands and $15 \mathrm{~m}$ spatial resolution for a ponchromatic band (Table 1). Seven of the OLI spectral bands compare closely to the shortwave spectral bands collected by the Enhaneed Thematic Mapper-Plus (ETM+) aboard Landsat 7. OLI will provide data for two new bands: a blue spectral band (Band 1) added principaly to provide ocean color data for coastal regions and a shortwaye infrared band ( $B$ and 9 ) alded to aid the detection of cirns clouds in OLI images. OLI will quantize raw image data to 12 bits and is requtred to produce data with signal-tomioise ratios as good as of better than ratios given ir: Table 2 .

Table 1. OLI Spectral Band and Spatial Resolution Specifications

\begin{tabular}{|c|c|c|c|c|c|}
\hline is & Band & $\begin{array}{l}\text { Munmum } \\
\text { Gower Batd } \\
\text { Bdge (nm) }\end{array}$ & Maximum Upper & $\begin{array}{l}\text { Center } \\
\text { Whyelength } \\
\text { (nm) }\end{array}$ & Spatial Resolution \\
\hline 1 & Coastal & 433 & 453 & 443 & $30 \mathrm{~m}$ \\
\hline 2 & Bitue & 450 & 515 & 482 & $30 \mathrm{~m}$ \\
\hline 3 & Green & 525 & 600 & 562 & $30 \mathrm{~m}$ \\
\hline 4 & Red & 630 & 680 & 655 & $30 \mathrm{~m}$ \\
\hline 5 & NIR & 845 & 885 & 865 & $30 \mathrm{~m}$ \\
\hline 6 & SWR & 1560 & 1660 & 1610 & $30 \mathrm{~m}$ \\
\hline 7 & SWIR 2 & 2100 & 2300 & 2200 & $30 \mathrm{~m}$ \\
\hline 8 & Panchromatic & 500 & 680 & 590 & $15 \mathrm{~m}$ \\
\hline 9 & Cinus & 1360 & 1390 & 1375 & $30 \mathrm{~m}$ \\
\hline
\end{tabular}


Table 2. OLI Saturation Radiance and Signal-to-Noise Ratio Specifcations

\begin{tabular}{|c|c|c|c|c|c|c|}
\hline \multirow[t]{2}{*}{ 雃: } & \multirow[t]{2}{*}{ Band } & \multirow{2}{*}{$\begin{array}{l}\text { Sartiration } \\
\text { Radlances } \\
\left(\mathrm{W} / \mathrm{m}^{2} \mathrm{st} \mathrm{\mu m}\right)\end{array}$} & \multicolumn{2}{|c|}{$\begin{array}{l}\text { Radiance Level for } \mathrm{SNR} \\
\qquad\left(\mathrm{W} / \mathrm{m}^{2} \text { sr } \mu \mathrm{m}\right)\end{array}$} & \multicolumn{2}{|c|}{ SNR Requirements } \\
\hline & & & $\begin{array}{c}\text { Typical, } \\
\text { LTypical }\end{array}$ & $\begin{array}{l}\text { High, } \\
\text { Lingh }\end{array}$ & $\frac{A t}{L_{\text {rypleal }}}$ & $\mathbf{L}_{\text {ftigh }}$ \\
\hline 1 & Coastal & 555 & 40 & $\$ 90$ & $\$ 30$ & 290 \\
\hline 2 & Blue & 581 & 40 & 190 & 130 & 360 \\
\hline 3 & Green & 544 & 30 & 194 & 100 & 390 \\
\hline 4 & Red & 462 & 22 & 50 & 90 & 340 \\
\hline 5 & NIR & 281 & 14 & 150 & 90 & 460 \\
\hline 6 & SWIR $]$ & 71.3 & 4.0 & 32 & 100 & 540 \\
\hline 7 & SWIR 2 & 24.3 & 1.7 & $\{1$ & 100 & 510 \\
\hline 8 & Panchromatie & 515 & 23 & 156 & 80 & 230 \\
\hline 9 & Cirnes & 6.0 & $N / A$ & 88.5 & 9 & $\mathrm{~N} / \mathrm{A}$ \\
\hline
\end{tabular}

The OLI employs a pushbroom sensor design incorporating a focal plan with long arrays of photosensitive detectors (Figure 2). A four-mirror anastigmatic telescope will focus incident radiation onto the focal plane while providing a $15-$ degree field-of view covering a $185 \mathrm{~km}$ across-txack ground swath from the nominal LDCM observatory altitke of 716 $\mathrm{km}$. Periodic sampling of the across-track detectors as the observatory flies forward along the ground tracks will form the multispectral digtal images. The detectors are divided into 14 modules arranged in an altemating patem along the centerline of the focal plane. Data will be acquired from over 6000 across-track detectors for each spectral band with the exception of the $15 \mathrm{~m}$ panchromatic band that requires over 12000 detectors. The spectral differentation will be achieved by interference filters arranged in a "butcherblock" pattert over the detector arrays in each module. Silicon PIN (SiPIN) detectors will collect the data for the visible and near-infrared spectral bands (Bands 1 to 4 and 8 ) while Mercury Cadmitm-Telluride (MgCdFe) detectors will be used for the shortwave infrared bands (Bands 6, 7, and 9). The OLI also contains intenal stimulation lamps and an external mechanism with solar difuser parels for nadiometric calibration.

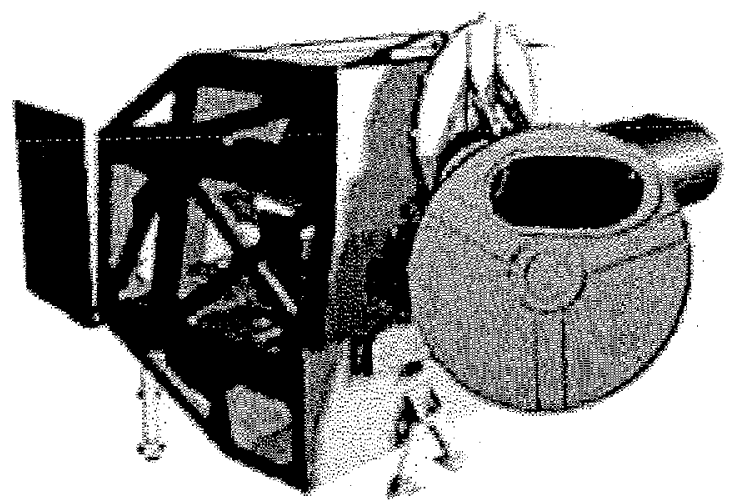

Figure 2. Drawing of the Operational Land Imager (coutesy of Ball Aerospace and Technology Comporation) 


\subsubsection{The Thermal Infrared Sensor (TIRS)}

NASA Goddard Space Flight Center (GSFC) is building the Themal Infrared Sensor (TRS). TIRS will collect digital tmages for two thermal (longwave) bands with a spatial resolution of $100 \mathrm{~m}$ (Table 3). In comparison, the ETM+ $15 \mathrm{~m}$ panchromatic band noise-equivalent-change+in-temperatute speciffcations.

Table 3. TIRS Spectral Band and Spatial Resolution Specifications

\begin{tabular}{|c|c|c|c|c|c|}
\hline Band & Band & $\begin{array}{c}\text { Center } \\
\text { Wavelength } \\
\text { (nm) }\end{array}$ & $\begin{array}{l}\text { Minimum } 10 \text { wer } \\
\text { Band } \operatorname{loge}(\mathrm{nm})\end{array}$ & $\begin{array}{l}\text { Maximun Upper } \\
\text { Band Eage (nm) }\end{array}$ & $\begin{array}{l}\text { Spatial } \\
\text { Resolution (m) }\end{array}$ \\
\hline 10 & Thermal 1 & 10800 & 10300 & 11300 & 100 \\
\hline 11 & Thermal 2 & 12000 & 11500 & 12500 & 100 \\
\hline
\end{tabular}

Table 4. TIRS Saturation Radiance and Notse-Equivalent-Change-in-Tenperature (NEDT) Specifications

\begin{tabular}{|c|c|c|c|}
\hline Band I & Saturation Temperature (K) & Saturation Radiance $\left(\mathrm{W} / \mathrm{m}^{2} \mathrm{st} \mu \mathrm{m}\right)$ & $\mathrm{NADT}$ at $300 \mathrm{~K}$ \\
\hline 10 & $360 \mathrm{~K}$ & 20.5 & $0.4 \mathrm{~K}$ \\
\hline 11 & $360 K$ & 17.8 & $0.4 \mathrm{~K}$ \\
\hline
\end{tabular}

The TIRS will also be a pushbroon sensor employing a focal plan with long arrays of photosensitive detectors (Figure 3). TIRS will employ cryogenically-cooled quantum-well-inftared-photodetector (QWIP) arrays divided into three modules arranged in an altemating pattern along the centerline of the focal plane. These modules will provide over 1850 element refractive telescope will band. TIRS will be the first spaceflight instrmment to use QWIP arrays. A fourview matching the $185 \mathrm{~km}$ across-tack swath of the (earth), an intemal blackbody, and a deep space view. A scene select mirror will flip the field-of-view between nadir teview is scheduled for the end of April 2010 .

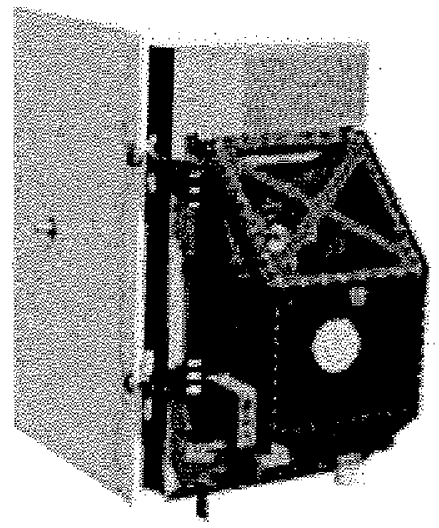

Figure 3. Drawing of the Thernal Infrared Sensor (TIRS) 


\subsection{The Ground System}

USGS will develop an LDCM Ground System providing the capabilities necessary for plaming; scheduling and operations of the LDCM Space Segment and the capabilities necessary to manage the seience data following transmission from the spacecraft. Embedded within the Ground System is the real time command and control subsystem for real-time operations of the Space Segment, known as the Mission Operations Element (MOE). A vendor tnder contract to NASA (with USGS and NASA funding) is implementing the MOE subsystem. The Mission Operations Center (MOC) will house the MOE, and at launch the primary MOC will reside physically at NASA GSFC.

The USGS will also develop the Data Processing and Archive System (DPAS) that will ingest, process, and archive all LDCM science and mission data returned from the LDCM observatory. The DPAS will also provide a public Web interface to allow users to search for and receve data products. The DPAS is located at the USGS Earth Resources Observation and Science (EROS) Center near Sioux Falls, South Dakota. USGS successfully conducted a Ground System critical design review in March 2010.

\subsubsection{The Mission Operations Element (MOE)}

LDCM data collection will be scheduled daily by the MOE within the MOC. The MOE will send commands to the satellife once every 24 hours via S-band communications from a netwok of ground receiving and fransmitting stations, the Ground Network Element (GNE). The daily schedule will be driven by a Long Term Acquistion Phan (LTAP-8) that sets priotities for collecting data along the satellite grourd paths covered in a particular 24 -hour period. OLI and TIRS will collect data jointly to provide coincident images of the sane surface areas. The MOE will nominally schedule the collection of 400 OLI and TIRS scenes per day where each scene will be a digital image covering a $185-\mathrm{by}-180 \mathrm{~km}$ surface area. The objective of schefuling and data collection will be to provide cloud-free coverage of the global landmass on a seasonal basis.

The MOE commands will also schedule the transmission of data from the observatory's X-band antenna to the GNE network of stations that receive the mission data for delivefy to the Data Processing and Archive system (DPAS). In addition, data will be transmitted to a network of international stations operated or under the sponsorship of foreign govermments referred to as Intertational Cooperators (ICs). The GNE will consist of three stations: one at USCS EROS in Sioux Falls, South Dakota; one at Gtmore Creek, Alaska; and one at Svalbard, Norway. The GNE sends all 400 scenes collected daily to the DPAS at USGS EROS in Sioux Falls, SD.

\subsubsection{The Data Processing and Archive System (DPAS)}

The DPAS will corsist of several subsystems: lngest (IS), Storage and Archive (SA), Subsetter (SS), Image Assessment (IAS), Produet Generation (PGS), and User Portal (UP). The SA will receive, store, and arebive the entire raw LDCM mission data sent from the GNE. The SA will perform all archive and storage functions in support of data ingest, inage assessment, product generation, and data access through the User Portat. Mussion data will be archived offine with an adtitional backup copy archived offsite.

The IS will process the OLI and TIRS file-based mission data into interval-based Level-0R archive (LORa) seience data and will create the associated inventory metadata. The SS will subset the OLI and TIRS LORa data into Landsat scene equivalent Level-0R (LORp) data for distribution or the generation of Level-1 products and their associated metadata.

The PGS will process each Levei ORp scene to radiometricaliy and geometrically correct the image dara. The radionetric correction will transform raw OLI data to digital counts linearly scaled to top-of thematmosphere spectral reflectance and will transforn raw TRS data to digital counts linearly scaled to at-aperture spectral radiance. The geometric correction will resample the radiometrically corrected data to create orthorectified images of Earth's surface registered to a cartographic projection. The corrected digital itnages along with metatata will be referred to as Level $1 T$ (L1T) data. The co-registered and terrain corrected OLA and TIRS data will be merged to create a single integrated Level-1 (LIT) data product. The PGS will routinely generate LI 1 products for each of the 400 scencs collected each day, as well as perform automated cloud cover and data quality assessmetse, and the results will stored in the LS database for subseguent analysis and rending. The IAS will be used to pefform OLI and TIRS data characterization, analysis, and trending, and the IAS will create the bias and calibration parameters requited for Level- 1 product generation. The User Portal will generate browse images from the LIT prodacts at multiple resolutions for interactive display and at full spatial resolution for download. The OL and TIRS Level-oR data are stored and maraged separately online until they are merged and integrated duning 1 I I product generation. 
The LORp and LIT WRS-2 scenes will constitute the standard LDCM science data products. The general puble will be able to search, browsc, and order LORp and LIT scenes through the User Portal. The UP will electronicalty transmit ordered scenes to LDCM data users at no cost to the users

\section{MISSION OPERATIONS CONCEPT}

The fundamental LDCM operations concept is to collect, archive, process, and distribute science data m a mamer consistent with the collection, archiving, processing, and distribution of sctence data from the Landsat 7 mission. To that end, the LDCM observatory will operate in a $716 \mathrm{~km}$ near-circular, near-polar, sun-synchronous orbit. The observatory will have a 16-day ground track repeat cycle with an equatorial crossing at $10.00 \mathrm{a} . \mathrm{m}$. ( +1.5 minutes) mean local time during the descending node of each orbit. In this orbit, the LDCM observatory will follow a secuence of fixed ground tracks (also known as paths) defined by the second Worldwide Reference System (WRS.2). WRS-2 is a path/row coorfinate system used to catalog the image data acquired from the Landsat 4, 5, and 7 satellites. These three satelltes have all followed the WRS-2 paths and all of the science data are referenced to this coordinate system. The LDCM science data will likewise be referenced to the WRS-2 as part of the ground processing and archiving perforned by the DPAS.

\section{MISSION STATUS}

The NASA Agency Management Council confinmed that the Landsat Data Continuity Mission is ready to proced to the final design and fabrication phase of mission development following a December, 2009 review at NASA Headquatters. An approval to incomporate TIRS into the LDCM observatory payload along with the OLI was a notable outcome of this review. The confimation followed the successful LDCM preliminary design review before an independent review board in July 2009.

The LDCM is now in the midst of the fnal design and fabrication phase. All major components of the mission architecture have been through successful crttical design reviews with the exception of TIRS; the TrRS critical design review is scheduled for April 2010. The mission level critical design review before the independent board will follow soon after in May 2010. NASA and USGS are managing the LDCM implementation towards a December 2012 launch through this process. The launch will be aboand a United Launch Alliance Atlas-V launch velicle.

\section{SUMMARY}

The Landsat program has provided an invaluable record of land cover and land use change for almost four dectes. Continuing the record is critical to understandiag the impacts of such change on climate, ecosystems, the environment, human health, the economy, society, and national securty. The need to lameh and operate the next Landsat satellite is turgen given the current states of Landsat 5 and Landsat 7. NASA and USGS are striving to laurleh and operate that satellite system, the LDCM, by December 2012 in order to prevent or minimize gaps in the coverage of the global land surface. The LDCM observatory, ground system, and mission operations concept will ensure the collection, archive, and distribution of the multispectral image data necessary to continue and improve upon the Landsat record. 